\title{
High magnetic field impact on the natural convection behaviour of a magnetic fluid
}

\author{
Anna Kraszewska $^{1} \cdot$ Lukasz Pyrda $^{1} \cdot$ Janusz Donizak $^{1}$
}

Received: 31 March 2017 / Accepted: 29 August 2017 /Published online: 12 September 2017

(C) The Author(s) 2017. This article is an open access publication

\begin{abstract}
An experimental analysis of high magnetic field impact on the natural convection of a paramagnetic fluid was conducted. Two geometries of experimental enclosures were investigated: Enclosure no. 1 with an aspect ratio of $0.5(A R$ aspect ratio $=$ height $/$ width $)$ and Enclosure no. 2 with a higher aspect ratio equal to 2.0. Various magnetic field inductions were analysed and representative parts of the obtained results are shown in the present paper. Estimations of the Nusselt number and spectral analysis of the fluid's behaviour were performed. The obtained results led to the conclusion that magnetic field has an immense impact on paramagnetic fluid flow, on heat transferred by the flow, as well as the flow structure. Introducing an additional buoyancy force to the system, acting toward intensification of the fluid motion, causes significant enhancement of the Nusselt number in both geometries. Additionally, a spectral analysis of temperature changes indicates that large flow structures occurring in natural convection cases at low frequencies, under the influence of magnetic field, transform towards smaller structures in the whole frequency band.
\end{abstract}

\section{Nomenclature}

a

AR

$b_{0 \max }$

$c_{\mathrm{p}}$

Base dimension $(\mathrm{m})$

Aspect ratio (-)

Magnetic induction in the centre of the magnet $(\mathrm{T})$

Heat capacity $(\mathrm{J} / \mathrm{kgK})$

Anna Kraszewska

kraszka@agh.edu.pl

1 Department of Fundamental Research in Energy Engineering, AGH University of Science and Technology, Al. Mickiewicza 30,

30-059 Krakow, Poland

$d$
$\mathbf{f}^{\mathbf{g}}$
$\mathbf{f}^{\mathbf{G}}$
$\mathbf{f}^{\text {mg }}$
$\mathbf{f}^{\mathbf{M G}}$
$F_{\mathrm{n}}$
$\mathbf{g}$
$\mathbf{H}$
Imaginary
$\mathrm{K}$
$\mathbf{M}$
$N$
$\mathrm{Nu}$
$Q_{\text {cond }}$
$Q_{\text {conv }}$
$Q_{\text {Fourier's_law }}$
$Q_{\text {loss }}$
$Q_{\text {net_cond }}$
$Q_{\text {net_conv }}$
Ra
Ra
Ra
Real
$t$
$T$
$T_{0}$
$T_{\mathrm{h}}$
$T_{\mathrm{c}}$
$x_{\mathrm{i}}$
$\alpha$
$\beta$
$\gamma$
$\lambda$
$\mu_{0}$
$\mu$

Height ( $m$ )

Gravitational force $\left(\mathrm{N} / \mathrm{m}^{3}\right)$

Gravitational buoyancy force $\left(\mathrm{N} / \mathrm{m}^{3}\right)$

Magnetic force $\left(\mathrm{N} / \mathrm{m}^{3}\right)$

Magnetic buoyancy force $\left(\mathrm{N} / \mathrm{m}^{3}\right)$

Discrete Fourier function (-)

Gravitational acceleration $\left(\mathrm{m}^{2} / \mathrm{s}\right)$

Intensity of a magnetic field $(\mathrm{A} / \mathrm{m})$

Imaginary part of transformed data (-)

Wave number (-)

Magnetization $(\mathrm{A} / \mathrm{m})$

Length of sequence i (-)

Nusselt number (-)

Conduction heat flux (W)

Convection heat flux (W)

Theoretical conduction heat flux (W)

Heat loss (W)

Net conduction heat flux (W)

Net convection heat flux (W)

Magnetic Rayleigh number (-)

Thermal Rayleigh number (-)

Thermo-magnetic Rayleigh number (-)

Real part of transformed data (-)

Time (s)

Temperature $\left({ }^{\circ} \mathrm{C}\right)$

Reference temperature $\left({ }^{\circ} \mathrm{C}\right)$

Temperature at the heated wall $\left({ }^{\circ} \mathrm{C}\right)$

Temperature at the cooled wall $\left({ }^{\circ} \mathrm{C}\right)$

Sequence length (-)

Thermal diffusivity $\left(\mathrm{m}^{2} / \mathrm{s}\right)$

Thermal expansion coefficient $(1 / \mathrm{K})$

Magnetization number (-)

Thermal conductivity ( $\mathrm{W} / \mathrm{mK}$ )

Magnetic permeability of vacuum $(\mathrm{H} / \mathrm{m})$

Dynamic viscosity $(\mathrm{kg} / \mathrm{ms})$ 


$\begin{array}{ll}\nu & \text { Kinematic viscosity }\left(\mathrm{m}^{2} / \mathrm{s}\right) \\ \rho & \text { Density }\left(\mathrm{kg} / \mathrm{m}^{3}\right) \\ \chi & \text { Mass magnetic susceptibility }\left(\mathrm{m}^{3} / \mathrm{kg}\right) \\ \chi_{\mathrm{v}} & \text { Volume magnetic susceptibility }(-)\end{array}$

\section{Introduction}

Natural convection processes, since they commonly occur in nature, as well as in industrial applications, have been studied extensively throughout the 20th and twenty-first century. Because of the buoyancy driven convection importance, especially as a means to enhance heat exchange, methods to improve heat transfer even more are often sought. One of the ways to achieve that is by introducing a new buoyancy driven force to the analysed system. In 1991 Braithwaite et al. [1] adopted an external magnetic field to enlarge and supress the convective motion of a paramagnetic fluid. This fact marked the beginning of a new era in convection research, directed to studies of a magnetic field impact on a weak magnetic fluid motion. This research field has been broadly investigated in the past two and a half decades. Tagawa et al. [2] developed a mathematical model equation for thermo-magnetic convection. Bednarz et al. [3-5] studied heat transfer and influence of different inclinations of a magnetic field on a paramagnetic fluid in cubical geometry in side-heated configurations. Kenjeres et al. [6,7] and Pyrda et al. [8] investigated various aspects, e.g. Prandtl number and magnetic susceptibility in transient and turbulent flow regimes in a cubical enclosure. Many other configurations have been studied, e.g. coaxial cylinders [9], thermosiphons [10], porous media [11]. Nowadays, a new field in the area is connected with nanofluids and analysing aspects like a concentration of nanoparticles or their sizes, and their influence on heat transfer in magnetic field [12-14].

Despite the considerable number of articles about the influence of different factors on natural convection, in 2012 Turan et al. [15] published research concerning laminar convection in systems with different aspect ratios (AR $=$ height/width). They concluded that AR has a crucial impact on heat transfer in investigated configurations. The field of thermo-magnetic convection lacks this kind of investigation work. To the authors best knowledge, there is no experimental data available in the literature concerning a strong magnetic field's influence on paramagnetic fluid convection in rectangular systems with different aspect ratios. Therefore, the authors performed experimental research of magnetic field impact on heat transfer and fluid flow behaviour in two different geometries: with $\mathrm{AR}=0.5$ and $\mathrm{AR}=2.0$.

\section{Theoretical background}

In natural convection phenomenon motion of a fluid is a result of a gravitational force acting on a fluid- $\mathbf{f}^{\mathbf{g}}$ :

$$
\mathbf{f}^{\mathbf{g}}=\mathbf{g} \rho
$$

Since the density of a fluid depends on a temperature, the magnitude of a gravitational force acting on a fluid with different temperature varies, creating a gravitational buoyancy force:

$\mathbf{f}^{\mathbf{G}}=\mathbf{g}\left(\rho-\rho_{0}\right)$

Taking into account the Boussinesq model, which states that the density of a fluid can be assumed as a constant for small temperature differences, except in the equation for buoyancy force, fluid density can be expressed as:

$\rho \simeq \rho_{0}\left(1-\beta\left(T-T_{0}\right)\right)$

Using relation (3) to eq. (2), gravitational buoyancy force takes following form:

$\mathbf{f}^{\mathbf{G}}=-\mathbf{g} \rho_{0} \beta\left(T-T_{0}\right)$

The obvious effect of a gravitational buoyancy force of a fluid in a gravitational field is the downward motion of a cold fluid, while the warm fluid particles are lifted.

Applying external magnetic field to a material causes the magnetic force to act on the material's electrons. The magnitude of the material's reaction to a magnetic field can be described by volume magnetic susceptibility:

$\chi_{v}=\mathbf{M} / \mathbf{H}$

and mass magnetic susceptibility:

$\chi=\chi_{v} / \rho$

A force acting on a paramagnetic fluid placed in an external magnetic field can be expressed as [16]:

$\mathbf{f}^{\mathbf{m g}}=\mu_{0}(\mathbf{M} \cdot \nabla) \mathbf{H}$

Noting (5) and knowing that magnetic induction $\mathbf{b}$ depends on the intensity of a magnetic field and on a magnetic permeability of the material, and also that for a paramagnetic fluid $\chi$ $<<1$, eq. (7) can be transformed into:

$\mathbf{f}^{\mathbf{m g}}=\frac{\chi}{2 \mu_{0}} \nabla \mathbf{b}^{2}$

Utilizing the above relation and Curie's law for paramagnetic materials, Tagawa et at. developed an equation to describe the magnetic buoyancy force [2]:

$\mathbf{f}^{\mathbf{M}}=-\left(1+\frac{1}{\beta T_{0}}\right) \frac{\chi_{0} \rho_{0}\left(T-T_{0}\right)}{2 \mu_{0}} \nabla \mathbf{b}^{2}$ 
Expression (9) indicates that the paramagnetic fluid particles are attracted to a square of a magnetic field's gradient if their temperature $T$ is lower than reference temperature $T_{0}$. Taking the above relations into consideration, an experimental enclosure filled with a paramagnetic fluid was placed in an upper half position in the magnet's working section, where the square of the magnetic field gradient was the highest, so the intensification of the fluid motion could be obtained.

\section{Experimental methodology}

\subsection{Measuring system}

The measuring system used in the proposed experimental research is presented in Fig. 1. It consists of two experimental enclosures placed, separately, in the bore of a superconducting magnet, a heater control system, a water thermo-stated bath with a constant temperature and data acquisition system connected to a personal computer. To calculate the magnetic field distribution and its gradient, besides the real dimensions of the system presented on Fig. 1. (right), the current densities in the internal and external coil should be taken into account. They were equal to $140.9 \cdot 10^{-6} \mathrm{~A} / \mathrm{m}^{2}$ and $167.3 \cdot 10^{-6} \mathrm{~A} / \mathrm{m}^{2}$ respectively at the maximum value $\left(b_{0 \max }=10 \mathrm{~T}\right)$ of the magnetic field inside the centre of the magnet.

Experimental enclosures are shown schematically in Fig. 2. Built from Plexiglass, rectangular vessels, of size $0.032 \mathrm{~m} \times 0.032 \mathrm{~m}$ in base and of $0.016 \mathrm{~m}$ (Enclosure A) and $0.064 \mathrm{~m}$ (Enclosure B) in height, were heated with a constant temperature from the bottom wall and isothermally cooled from the top. Four remaining vertical walls were insulated. The bottom wall consisted of a copper plate heated with nichrome wire connected to a DC power supply. The electric voltage and current were measured with a multi-meter. A top wall was also composed of a copper plate with a built in cooling chamber, which was cooled by cold water running from a thermostat. Because an ambient temperature in the magnet's working section was $18{ }^{\circ} \mathrm{C}$, in order to minimize the heat losses from the system, the temperature on the cooled wall was set to be the same. The temperature of the heated and cooled walls were measured with six T-type thermocouples inserted into the small holes in each plate. Five (Enclosure no. 1) and six (Enclosure no. 2) thermocouples (Fig. 2) were inserted into small holes in one wall of the experimental enclosure at $6 \mathrm{~mm}$ deep and measured the temperature changes of the fluid during the tests.

\subsection{Working magnetic fluid}

An experimental analyses for both geometries were performed about a year apart and because of that the first fluid degraded. Therefore two slightly different fluids were used: fluid 1 (F1) for Enclosure no.1, and fluid 2 (F2) for Enclosure no. 2. The working fluids were $50 \%$ volume glycerol aqueous solutions. Since both water and glycerol present diamagnetic properties, an addition of $0.8 \mathrm{~mol} /(\mathrm{kg}$ of solution) of gadolinium nitrate hexahydrate $\mathrm{Gd}\left(\mathrm{NO}_{3}\right)_{3} \cdot 6 \mathrm{H}_{2} \mathrm{O}$ crystals had to be made to make them paramagnetic. The main goal was to maintain similar magnetic properties of the fluids (mass magnetic susceptibility), which was achieved during the preparation of the second fluid F2, but the viscosity, density and therefore, the thermal expansion coefficient, for fluid F1 are slightly different than for fluid F2.

Fluid properties were measured and are listed in Table 1. The densities of the working fluids were measured with a pycnometer and thermal expansion coefficient was calculated. The magnetic susceptibility of the fluids was gauged with a magnetic susceptibility balance using the Evan's method. Viscosities were meted using an Ubbelohde viscometer and other properties were taken from [17].

\subsection{The measurement procedure}

The first step of the measurement procedure was connected with estimating the heat losses from the system in order to
Fig. 1 Schematic view of the experimental setup (left) and dimensions of the magnet's coils (right)
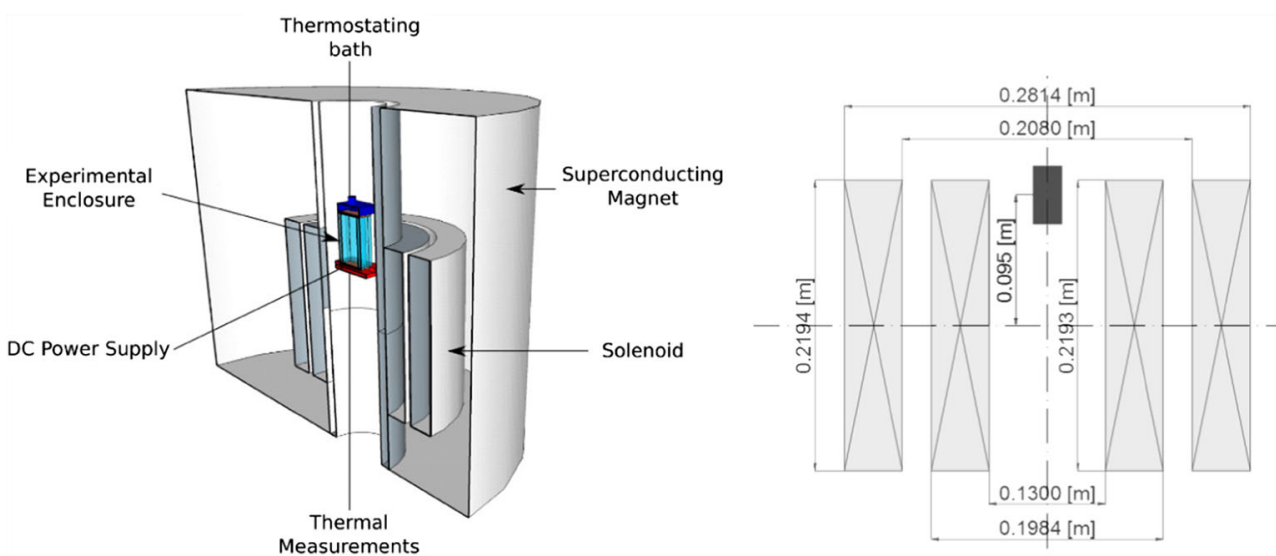
Fig. 2 a Experimental geometries: Enclosure no. 1 with $\mathrm{AR}=0.5$ and Enclosure no. 2 with $\mathrm{AR}=2.0 ; \mathbf{b}$ thermocouple's locations in $\mathrm{mm}$

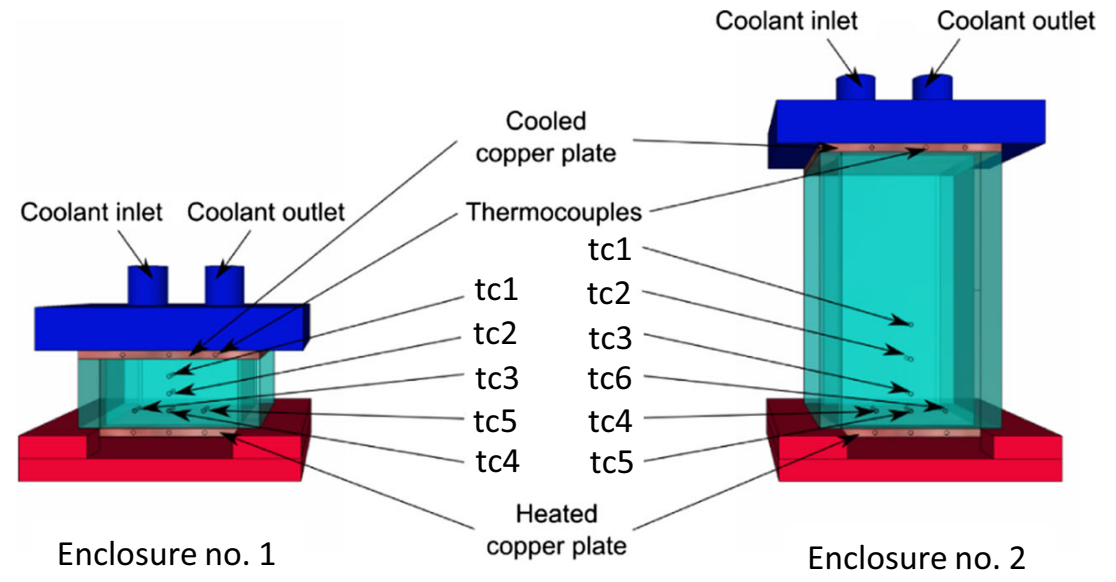

(b)
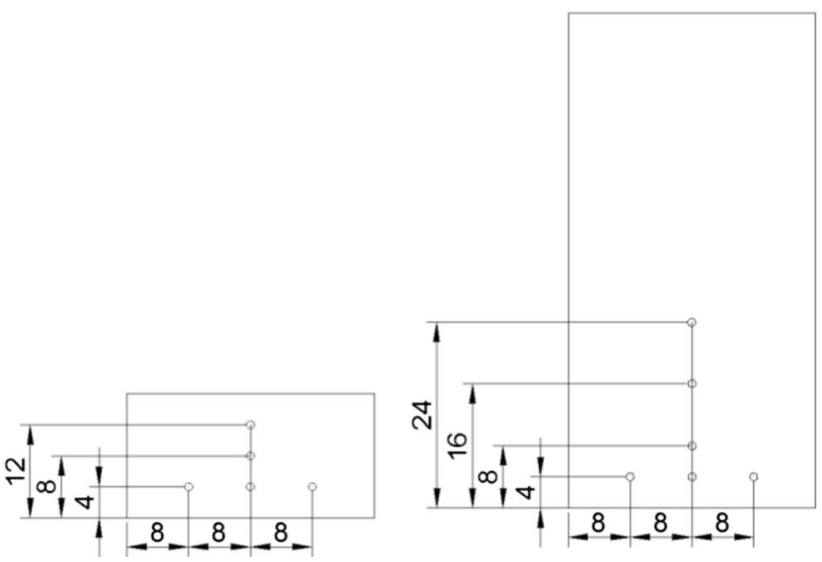

calculate the Nusselt number. Enclosure no. 1 was filled with distilled water and placed in the predestined position in the magnet's working section, but the vessel was rotated 180 degrees in the reversed Rayleigh- Bénard position. This configuration allowed to reach a temperature stratification - a conduction state without convective fluid motion. After setting the temperature at the bottom and top walls and waiting for the fluid and temperature fields to stabilize, linear temperature distribution was achieved and heating power was measured. Assuming a one-dimensional conductive heat flow, the heat flux can be calculated from Fourier's law of conduction (see section 4.1.). Therefore, a difference between heat flux calculated from Fourier's Law and measured heat flux on a heated wall is the heat loss of a measuring system. The same procedure was used to calculate heat losses from Enclosure no. 2. Heat losses from both experimental geometries can be approximated from:

$Q_{\text {loss } 1} \propto 0.090 \cdot \Delta T$

$Q_{\text {loss } 2} \propto 0.083 \cdot \Delta T$

The second step of the experimental analysis was connected with natural convection and thermo-magnetic convection measurements. The experimental enclosure was rotated back to the Rayleigh-Bénard configuration and the temperature difference between the thermally active walls was set. Three differences between the thermally active walls were investigated $-3,5$ and $11{ }^{\circ} \mathrm{C}$. After a thermal stabilization was achieved, 15-min recording of temperature took place. Subsequently the magnetic induction was set at the desired value, the experimental system was left to stabilize and then

Table 1 Properties of the working fluid at $25^{\circ} \mathrm{C}$

\begin{tabular}{llll}
\hline Property & \multicolumn{2}{l}{ Value } & \multirow{2}{*}{ Unit } \\
\cline { 2 - 3 } & F1 & F2 & \\
\hline Heat capacity $c_{p}$ & $2.92 \cdot 10^{3}$ & $2.92 \cdot 10^{3}$ & $\mathrm{~J} / \mathrm{kgK}$ \\
Thermal diffusivity $\alpha$ & $9.13 \cdot 10^{-8}$ & $7.55 \cdot 10^{-8}$ & $\mathrm{~m}^{2} / \mathrm{s}$ \\
Thermal expansion coefficient $\beta$ & $4.3 \cdot 10^{-4}$ & $1.46 \cdot 10^{-4}$ & $1 / \mathrm{K}$ \\
Dynamic viscosity $\mu$ & $1.30 \cdot 10^{-2}$ & $1.56 \cdot 10^{-2}$ & $\mathrm{~kg} / \mathrm{ms}$ \\
Thermal conductivity $\lambda$ & 0.376 & 0.376 & $\mathrm{~W} / \mathrm{mK}$ \\
Kinematic viscosity $\nu$ & $9.25 \cdot 10^{-6}$ & $1.10 \cdot 10^{-5}$ & $\mathrm{~m} / \mathrm{s}$ \\
Density $\rho$ & 1411 & 1418.1 & $\mathrm{~kg} / \mathrm{m}^{3}$ \\
Mass magnetic susceptibility $\chi_{\mathrm{m}}$ & $2.39 \cdot 10^{-7}$ & $2.58 \cdot 10^{-7}$ & $\mathrm{~m}^{3} / \mathrm{kg}$ \\
\hline
\end{tabular}


the measurement of temperature took place. Those steps were repeated for the values of magnetic induction $b_{0 \max }$ from $0 \mathrm{~T}$ up to $10 \mathrm{~T}$.

For both analyzed enclosures, the procedure was the same.

\section{Analysis of temperature signals}

The temperature signals, recorded during the experimental research, allowed for the investigation of two aspects the heat transfer in the analysed systems and the behaviour of the paramagnetic fluid's flow subjected to an external magnetic field.

\subsection{Analysis of heat transfer in the system}

The heat transfer rate was established by calculation of the Nusselt number, which is a dimensionless criterion displaying heat transfer in the system. From definition, the Nusselt number is a ratio of convective heat flux to conducted heat flux:

$\mathrm{Nu}=Q_{\text {net_conv }} / Q_{\text {net_cond }}$

The net conduction $\left(Q_{\text {net_cond }}\right)$ and net convection ( $\left.Q_{\text {net_conv }}\right)$ heat fluxes were computed by Ozoe and Churchill method [18], which is based on the following relations:

$Q_{\text {net_cond }}=Q_{\text {cond }}-Q_{\text {loss }}$

$Q_{\text {net_conv }}=Q_{\text {conv }}-Q_{\text {loss }}$

As said in section 3.3, it was assumed that the heat losses depend only on the temperature of the heated wall. So as a step one in determining the Nusselt number, the conduction measurements were made and the heat losses were calculated from:

$Q_{\text {loss }}=Q_{\text {cond }}-Q_{\text {Fourier's_law }}$

where

$Q_{\text {Fourier's } \_ \text {law }}=\frac{\mathrm{a}^{2} \lambda \Delta T}{d}$

The heat flux was computed for a conduction area of $0.032 \mathrm{~m} \times 0.032 \mathrm{~m}$ (base wall dimensions in both geometries). So the Nusselt number, with the usage of eqs. (13), (15) and (16) can be expressed as:

$\mathrm{Nu}=\frac{Q_{\text {conv }}-Q_{\text {loss }}}{\frac{\mathrm{a}^{2} \lambda \Delta T}{d}}$

where the convection heat flux $\left(\mathrm{Q}_{\text {conv }}\right)$ is given by the difference between heat flux measured during experiments and heat losses from the system.
The results of the heat transfer analysis are shown as a function of the thermo-magnetic Rayleigh number, which is defined as follows:

$R a_{T M}=R a_{T}+R a_{M}$

where $\mathrm{Ra}_{T}$ is the thermal Rayleigh number, $R \mathrm{a}_{\mathrm{M}}$ is the magnetic Rayleigh number and $\gamma$ is the magnetization number:

$\operatorname{Ra}_{\mathrm{T}}=\frac{\mathbf{g} \beta\left(T_{\mathrm{h}}-T_{\mathrm{c}}\right) d^{3}}{\alpha \nu}$

$\mathrm{Ra}_{\mathrm{M}}=\left(1+\frac{1}{\beta T_{0}}\right)\left[\frac{\mathbf{g} \gamma \beta\left(T_{\mathrm{h}}-T_{\mathrm{c}}\right) d^{3}}{2 \alpha \nu}\right]$

$\gamma=\frac{\chi\left|\mathrm{b}_{0}\right|_{\max }^{2}}{\rho \mu_{\mathrm{m}} \mathbf{g} d}$

\subsection{Flow behaviour analysis}

Signals from the thermocouples inserted into the experimental enclosures allowed for the examination of the flow behaviour. This spectral analysis was obtained through the Fast Fourier Transform (FFT), which computes the Discrete Fourier Transform (DFT) of a sequence:

$F_{n}=\sum_{i=0}^{N-1} x_{i} e^{-\frac{2 \pi i n}{N} n}$

The spectral functions of a scalar field (e.g. temperature, pressure, density, concentration) are very useful tools in analyzing a turbulent transport mechanism. Thus, assuming that the turbulence is homogenous, power density or spectrum may be calculated with the utilization of FFT:

Power density $\left(e^{j \omega}\right)=\sum_{m=-\infty}^{\infty} r_{x x}(m) e^{-j \omega m}$

and with the use of the Peridogram method, which estimates power as Time-Integral Square Amplitude (TISA) from amplitude obtained with FFT:

Power density $($ TISA $)=\frac{\Delta t\left(\text { Real }^{2}+\text { Imaginary }^{2}\right)}{n}$

Temperature spectral functions generally depend on energy dissipation, thermal diffusivity, viscosity and temperature. In some ranges of frequency, spectral functions do not depend on the diffusion processes, and hence do not rely on kinematic viscosity and thermal diffusivity. This subrange is called the inertial-convective [19] region and in this range spectral function has an inclination of wave number $\mathrm{K}$ with a $-5 / 3$ exponent. In cases where thermal diffusivity becomes more important, the spectral function 
Fig. 3 Results of Nusselt number calculations for Enclosure no. 1 (left) and Enclosure no.2 (right) as a function of a thermo-magnetic Rayleigh number

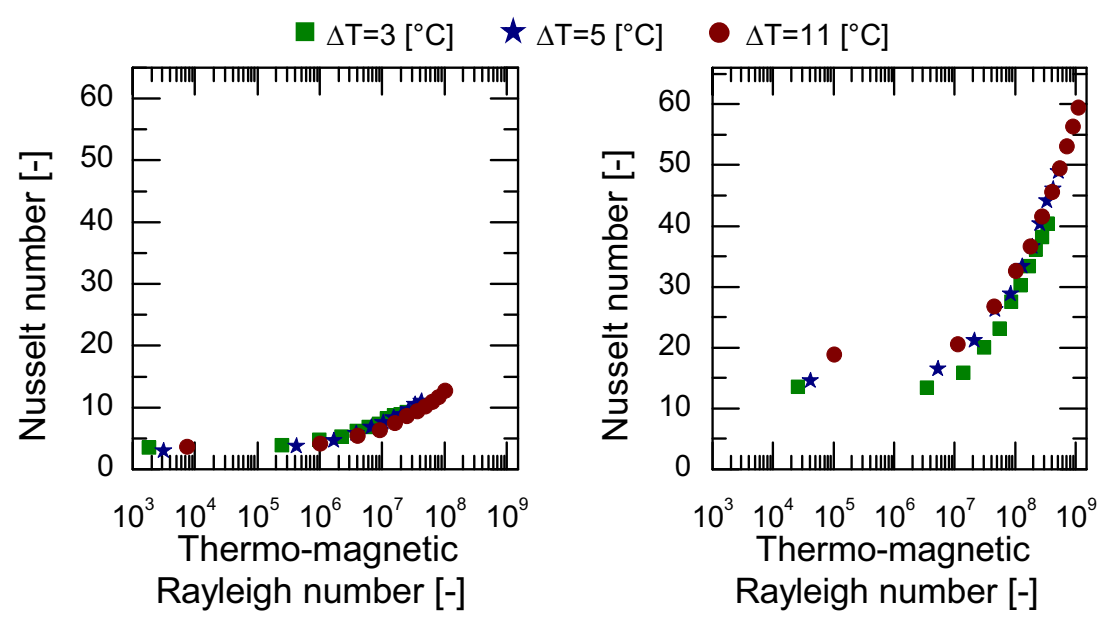

has an inclination of reverse wave number, and this range is called viscous-diffusive [19].

The attained results, in the form of an amplitude versus frequency and a power spectrum of the fluid flow field, were used to analyse the fluid behaviour in a thermo-magnetic convection.

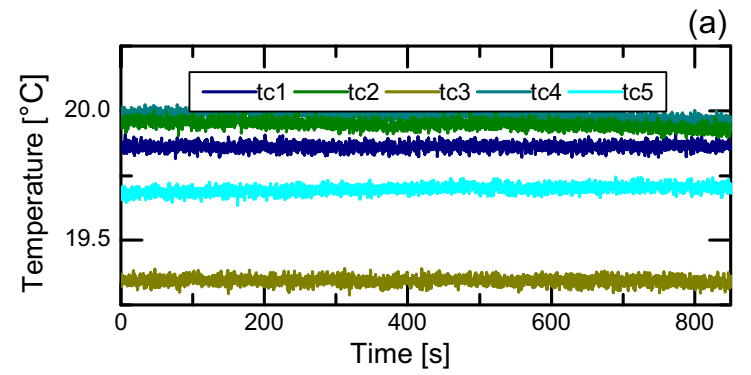

(c)
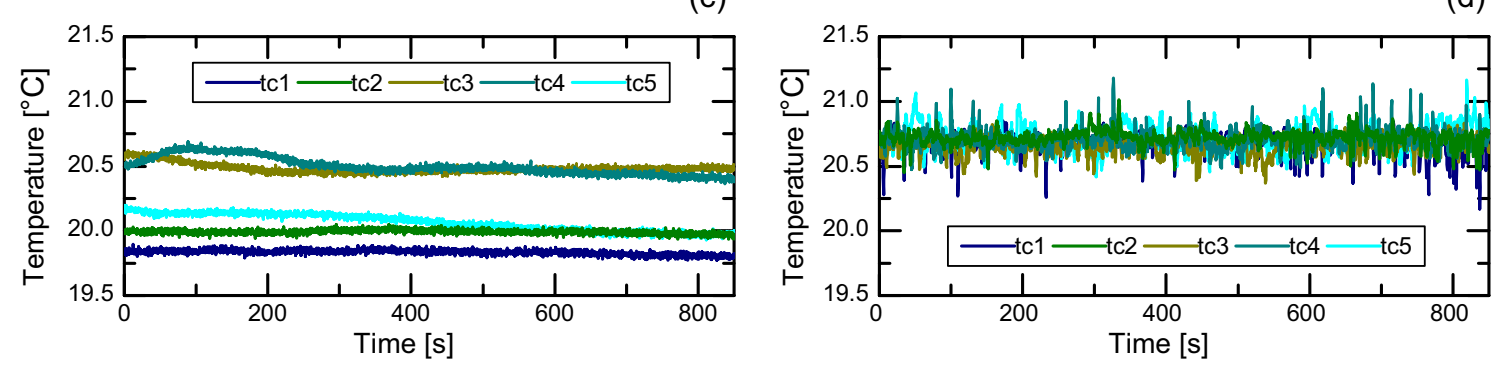

(e)
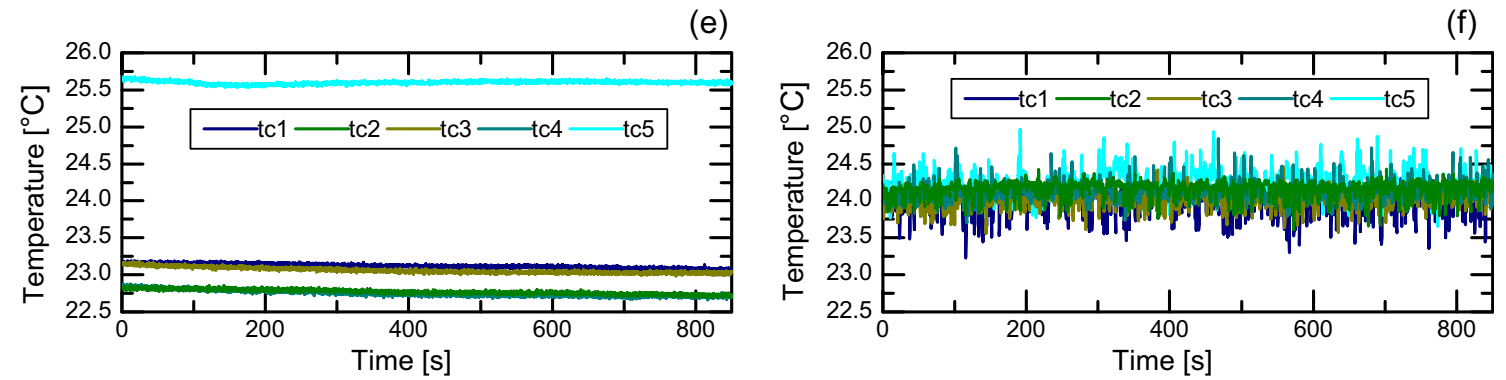

Fig. 4 Changes of a fluid's temperature during experiments in Enclosure no.1: (a) $b_{0 \max }=0 \mathrm{~T}, \Delta T=3{ }^{\circ} \mathrm{C}$, (b) $b_{0 \max }=10 \mathrm{~T}, \Delta T=3{ }^{\circ} \mathrm{C},(\mathrm{c}) b_{0 \max }=0 \mathrm{~T}$, $\Delta T=5^{\circ} \mathrm{C}$, (d) $b_{0 \max }=10 \mathrm{~T}, \Delta T=5^{\circ} \mathrm{C}$, (e) $b_{0 \max }=0 \mathrm{~T}, \Delta T=11^{\circ} \mathrm{C}$, (f) $b_{0 \max }=10 \mathrm{~T}, \Delta T=11^{\circ} \mathrm{C}$ 
(a)

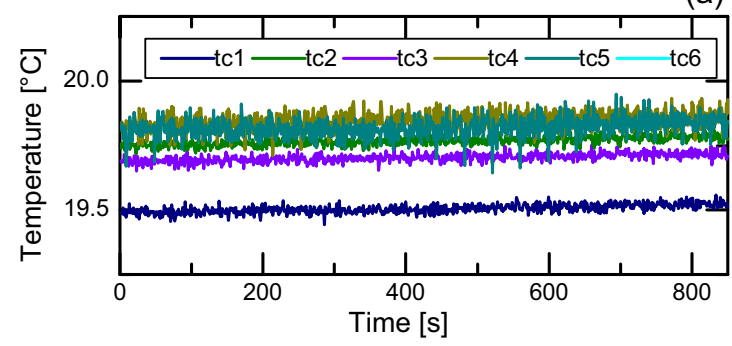

(c)

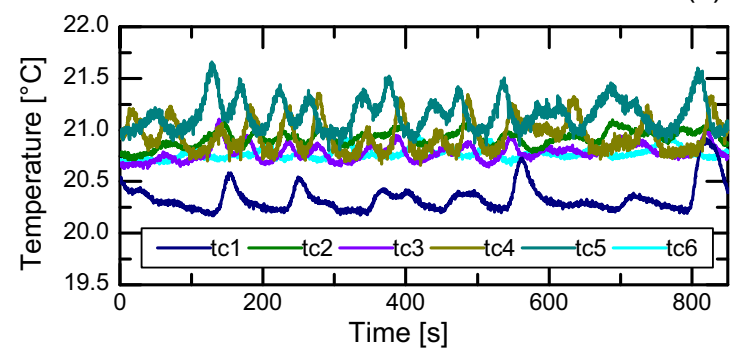

(e)

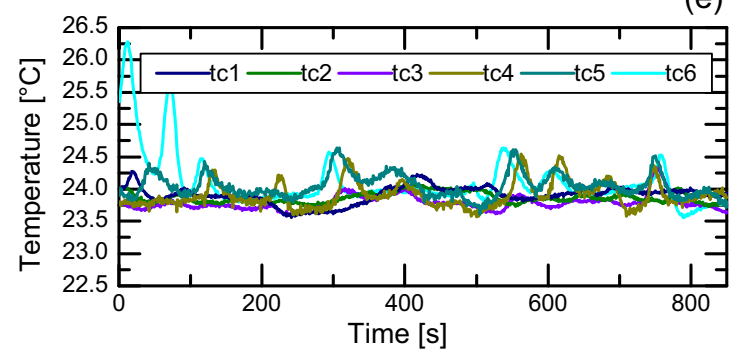

(b)

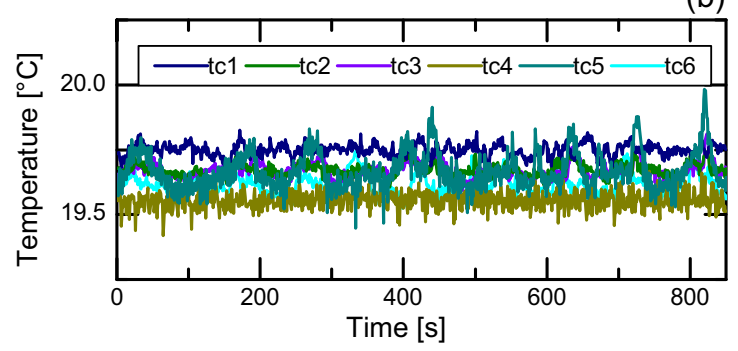

(d)

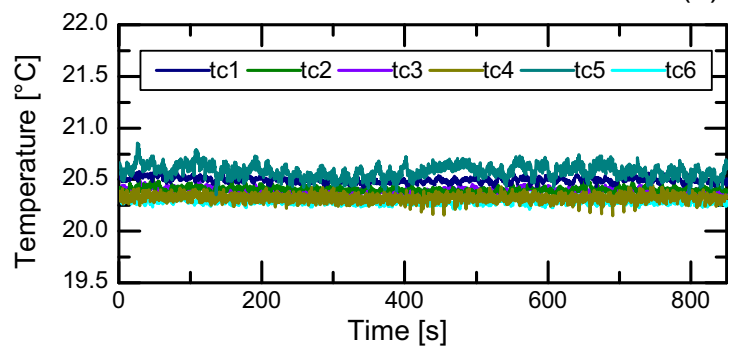

(f)

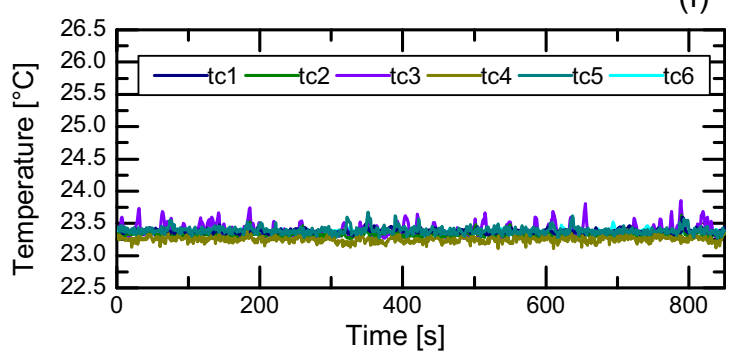

Fig. 5 Changes of a fluid's temperature during experiments in Enclosure no.2: (a) $b_{0 \max }=0 \mathrm{~T}, \Delta T=3{ }^{\circ} \mathrm{C}$, (b $b_{0 \max }=10 \mathrm{~T}, \Delta T=3{ }^{\circ} \mathrm{C}$, (c) $b_{0 \max }=0 \mathrm{~T}$, $\Delta T=5^{\circ} \mathrm{C}$, (d) $b_{0 \max }=10 \mathrm{~T}, \Delta T=5^{\circ} \mathrm{C}$, (e) $b_{0 \max }=0 \mathrm{~T}, \Delta T=11^{\circ} \mathrm{C}$, (f) $b_{0 \max }=10 \mathrm{~T}, \Delta T=11^{\circ} \mathrm{C}$

aspect ratio of 0.5 , the Nusselt number is significantly lower than for Enclosure no. 2 with an aspect ratio of 2.0. For natural convection cases, where the magnetic Rayleigh number is equal to 0 and therefore $\mathrm{Ra}_{\mathrm{TM}}=\mathrm{Ra}_{\mathrm{T}}$ according to eq. (18), in Enclosure no. 1 Nusselt number values start from 2.95 for $\Delta T=5^{\circ} \mathrm{C}, 3.46$ for $\Delta T=3{ }^{\circ} \mathrm{C}$ and 3.62 for $\Delta T=11^{\circ} \mathrm{C}$ while in Enclosure no. 2 it is $13.45,14.50$ and 18.82 for $\Delta T=3,5$ and $11{ }^{\circ} \mathrm{C}$ respectively. After an application of a magnetic field to the system, in both geometries, the Nusselt number increases. For a magnetic field of $10 \mathrm{~T}$, the increase of heat transfer rate in Enclosure no. 1 for $\Delta T=3{ }^{\circ} \mathrm{C}$ is over $250 \%$ to $\mathrm{Nu}=9.21$, while in every other case improvement in the Nusselt number is over $300 \%$. In Enclosure no. 1 it reaches values: 11.02 for $\Delta T=5^{\circ} \mathrm{C}$ and 12.66 for $\Delta T=11{ }^{\circ} \mathrm{C}$ and in Enclosure no. 2 to $40.34,48.91$ and 59.33 for $\Delta T=3,5$ and $11^{\circ} \mathrm{C}$, respectively.

Figures 4 and 5 represent the changes of fluid temperature during the 15 -min period. Parts a,c and e show natural convection cases for $\Delta T=3,5,11{ }^{\circ} \mathrm{C}$ respectively, and parts $\mathrm{b}, \mathrm{d}$ and $\mathrm{f}$ report thermo-magnetic convection cases at a maximal value of a magnetic induction $10 \mathrm{~T}$. Colours of the lines in the presented graphs present thermocouples placed in the experimental enclosure in particular locations, as shown in Fig. 2.

Natural convection measurements for Enclosure no.1 show temperature lines as stable and horizontal (Fig. 4 a, c, d). The thermal Rayleigh number for Enclosure no.1 was $1.84 \cdot 10^{3}$, $3.12 \cdot 10^{3}$ and $7.64 \cdot 10^{3}$ for $\Delta T=3,5,11^{\circ} \mathrm{C}$ respectively. For the geometry with the higher aspect ratio, in cases where the temperature difference was higher than $3{ }^{\circ} \mathrm{C}$ (Fig. $5 \mathrm{c}$, e), the temperature field is not as stable. Temperature lines show a wavy character, which may indicate an existence of flow structures rotating in the enclosure with a low frequency. The thermal Rayleigh numbers for Enclosure no. 2 were as follows: $\operatorname{Ra}_{\mathrm{T}}=3.14 \cdot 10^{4} ; 4.05 \cdot 10^{4}$ and $9.19 \cdot 10^{4}$ for $\Delta T=3$, $5,11{ }^{\circ} \mathrm{C}$ respectively. During the stepwise increase of the magnetic induction up to $10 \mathrm{~T}$, temperature signals from the thermocouples tend to unify temperature values at all thermocouple positions and start to oscillate over time. This suggests an increase in fluid velocity and a change of a fluid flow pattern during this process.

Figures 6 and 7 show the results of the fast Fourier analysis in amplitude versus frequency form. Parts a, $\mathrm{c}$ and e represent natural convection cases for $\Delta T=3,5,11^{\circ} \mathrm{C}$ respectively, and 
Fig. 6 Amplitude of a fluid's temperature oscillations as a function of frequency in Enclosure no.1: (a) $b_{0 \max }=0 \mathrm{~T}$, $\Delta T=3{ }^{\circ} \mathrm{C}$, (b) $b_{0 \max }=10 \mathrm{~T}$, $\Delta T=3{ }^{\circ} \mathrm{C}$, (c) $b_{0 \max }=0 \mathrm{~T}$, $\Delta T=5^{\circ} \mathrm{C}$, (d) $b_{0 \max }=10 \mathrm{~T}$, $\Delta T=5^{\circ} \mathrm{C}$, (e) $b_{0 \max }=0 \mathrm{~T}$, $\Delta T=11^{\circ} \mathrm{C}$, (f) $b_{0 \text { max }}=10 \mathrm{~T}$, $\Delta T=11^{\circ} \mathrm{C}$ (a)
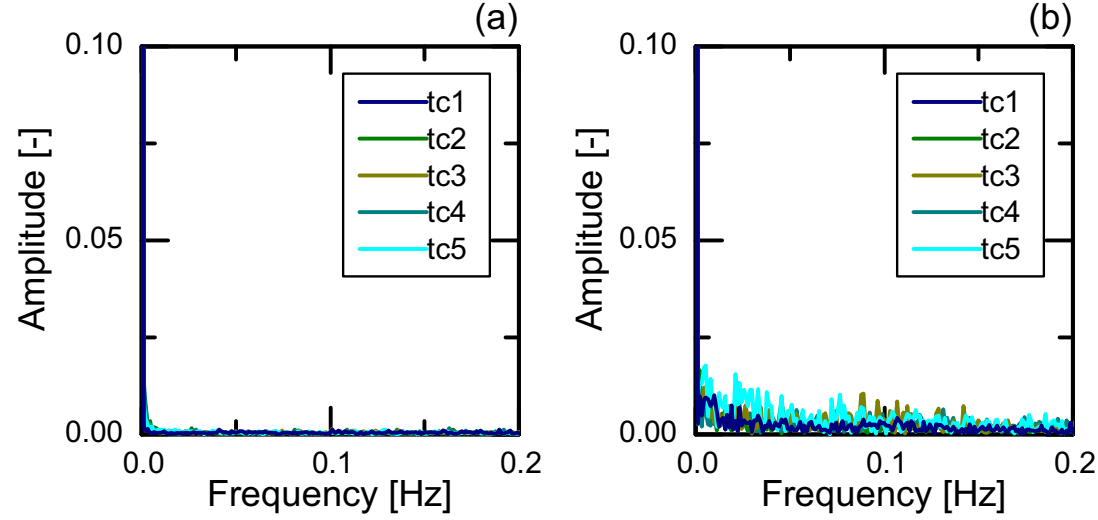

(c)
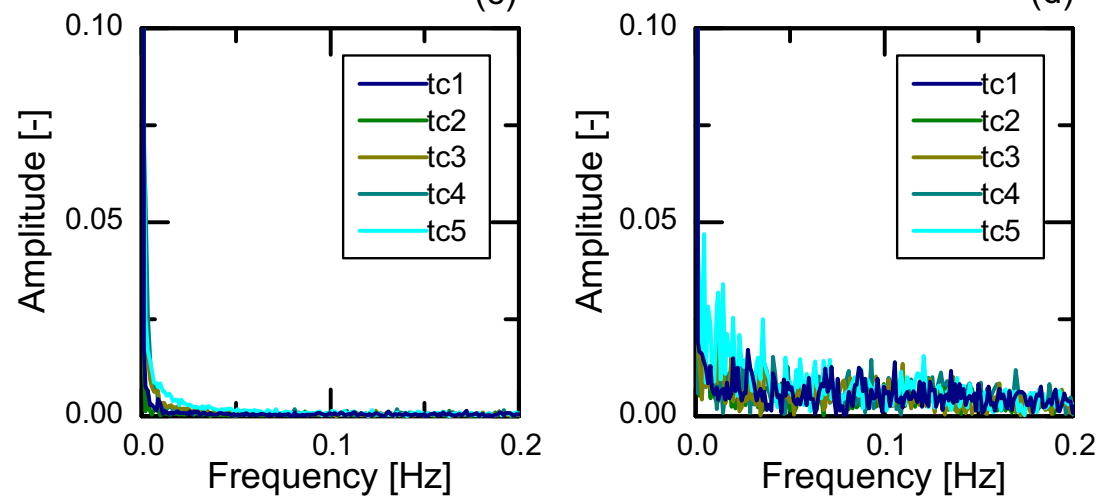

(e)

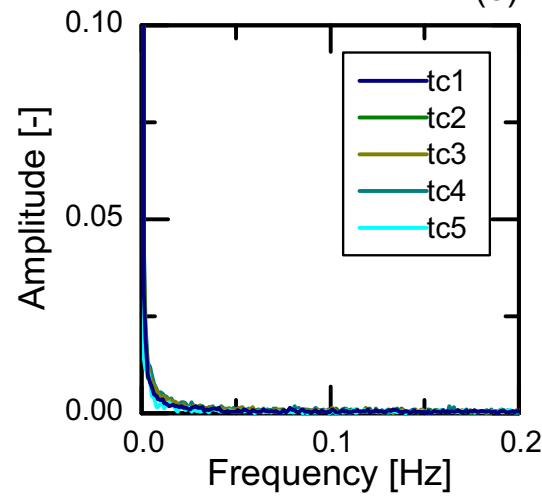

(b)

(d)

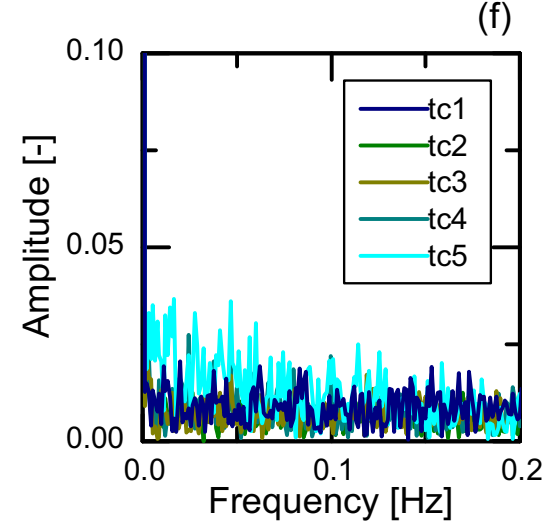

(f) parts $\mathrm{b}, \mathrm{d}$ and $\mathrm{f}$ thermo-magnetic convection cases at the maximal value of the magnetic induction - $10 \mathrm{~T}$.

For $\Delta T=3,5$ and $11{ }^{\circ} \mathrm{C}$ in Enclosure no. 1 fluid flow is steady and no temperature amplitude peaks can be observed. After applying magnetic induction to the system, the flow becomes faster and temperature oscillations are more frequent. In the thermo-magnetic convection one thermocouple shows behaviour different from the others. This thermocouple 'tc5' was placed in the bottom right corner of the enclosure and is represented by cyan colour in the figure. The amplitude of fluctuations is higher than for the other thermocouples. This may indicate an appearance of a small vortical structure which is moving apart from the main flow. In Enclosure no.2, with a higher aspect ratio, high amplitudes appear for small frequencies at natural convection cases (c and e parts in Fig. 7). After applying an external magnetic field to the system, a decrease of higher amplitudes can be observed. The amplitudes of temperature oscillations became less intensive than for the results for the natural convection case but appears in the wider range of the frequency band. This suggests a faster movement of the fluid in the experimental enclosure and confirms the intensification impact of the magnetic field to the paramagnetic fluid flow.

Figures 8 and 9 present the results of the fast Fourier analysis as a power spectrum. Parts a, $\mathrm{c}$ and e represent natural convection cases for $\Delta T=3,5,11^{\circ} \mathrm{C}$ respectively, and parts $\mathrm{b}, \mathrm{d}$ and $\mathrm{f}$ thermo-magnetic convection cases at the maximal value of a magnetic induction - $10 \mathrm{~T}$. 
Fig. 7 Amplitude of a fluid's temperature oscillations as a function of frequency in Enclosure no.2: (a) $b_{0 \max }=0 \mathrm{~T}$, $\Delta T=3{ }^{\circ} \mathrm{C}$, (b) $b_{0 \max }=10 \mathrm{~T}$, $\Delta T=3{ }^{\circ} \mathrm{C}$, (c) $b_{0 \max }=0 \mathrm{~T}$, $\Delta T=5^{\circ} \mathrm{C}$, (d) $b_{0 \max }=10 \mathrm{~T}$, $\Delta T=5^{\circ} \mathrm{C}$, (e) $b_{0 \max }=0 \mathrm{~T}$, $\Delta T=11^{\circ} \mathrm{C}$, (f) $b_{0 \text { max }}=10 \mathrm{~T}$, $\Delta T=11^{\circ} \mathrm{C}$
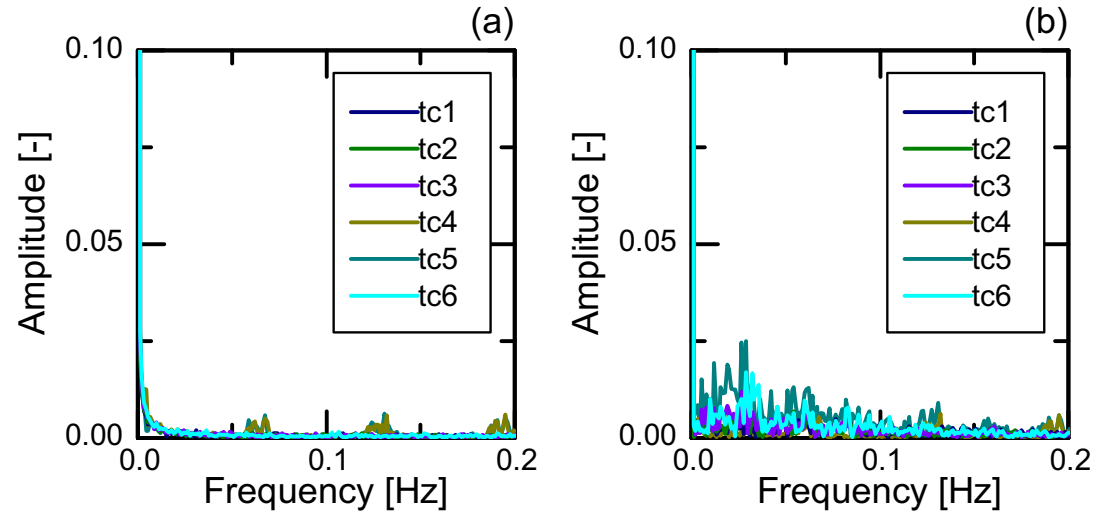

(c)
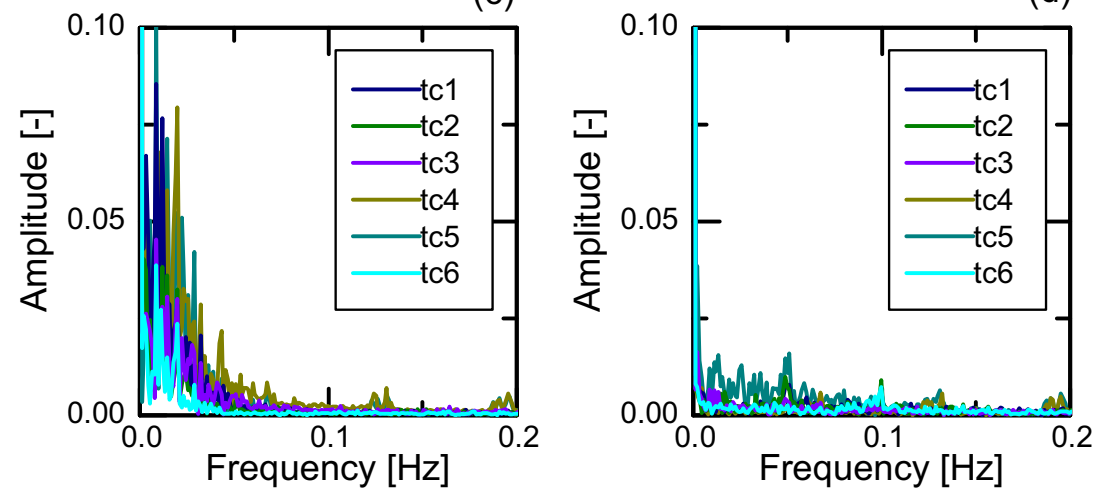

(e)
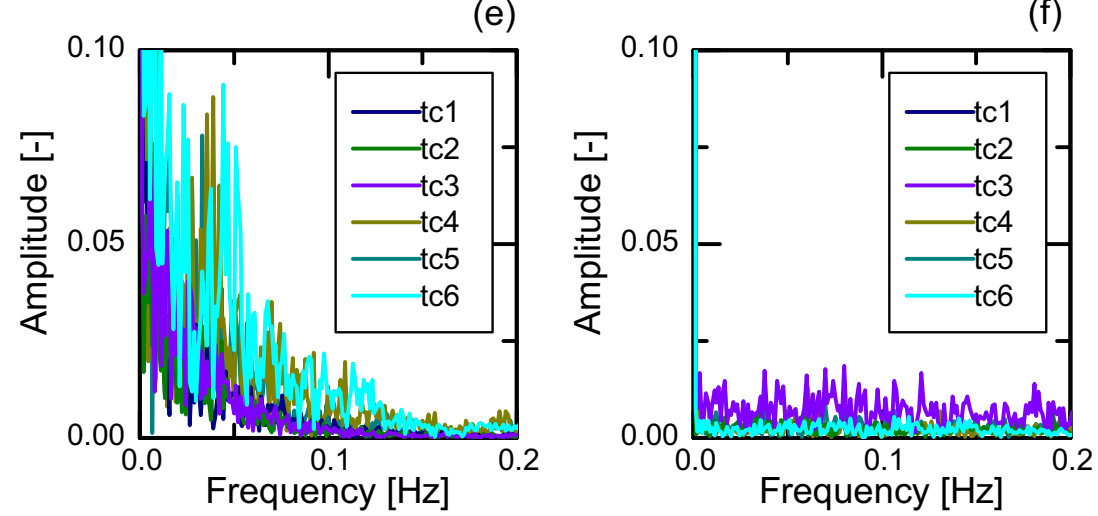

Taking into account the theory of turbulent energy flow, as well as the Kolmogorov theorem, certain frequency regions can be distinguished for inertial and viscous-diffusive regimes (see section 4.2). Fluctuations of physical quantities observed as a function of time at a fixed point of space (thermocouples placed in experimental enclosures) are caused by turbulent vortex flowing through this point. These whirls are constantly changing from the largest scales, close to the average scales, to the smallest structures in which turbulent kinetic energy dissipation occurs. With each whirl size, a specific frequency of fluctuations can be observed in a given flow. The largest whirls exhibit the lowest frequency, while the smaller whirls participate in higher frequencies. Therefore, fluctuations occur continuously throughout the frequency band. Internal energy transport plays an important role in the distribution of energy in individual frequency sub-regions. Information about turbulence macroscale can be obtained by analysing the corresponding spectral functions. Colloquially, on the power spectrum, one can distinguish certain frequency regions for which there are inertia and viscous-diffusive subspaces of the wave number. The given patterns show the powers that speak precisely of these ranges.

Spectral analysis in natural convection cases for geometry with a small aspect ratio represents the flat character of the spectrum, which is specific for stable, regular and laminar flows. For $\Delta T=5{ }^{\circ} \mathrm{C}$ a match to a viscous-diffusive regime for small frequencies can be observed. For the highest temperature difference $\Delta T=11^{\circ} \mathrm{C}$ a partial match to an inertial- 
Fig. 8 Power density as a function of a frequency in Enclosure no.1: (a) $b_{0 \max }=0 \mathrm{~T}$, $\Delta T=3{ }^{\circ} \mathrm{C}$, (b) $b_{0 \max }=10 \mathrm{~T}$, $\Delta T=3{ }^{\circ} \mathrm{C}$, (c) $b_{0 \max }=0 \mathrm{~T}$, $\Delta T=5^{\circ} \mathrm{C}$, (d) $b_{0 \max }=10 \mathrm{~T}$, $\Delta T=5{ }^{\circ} \mathrm{C}$, (e) $b_{0 \max }=0 \mathrm{~T}$, $\Delta T=11^{\circ} \mathrm{C}$, (f) $b_{0 \max }=10 \mathrm{~T}$, $\Delta T=11^{\circ} \mathrm{C}$ (a)
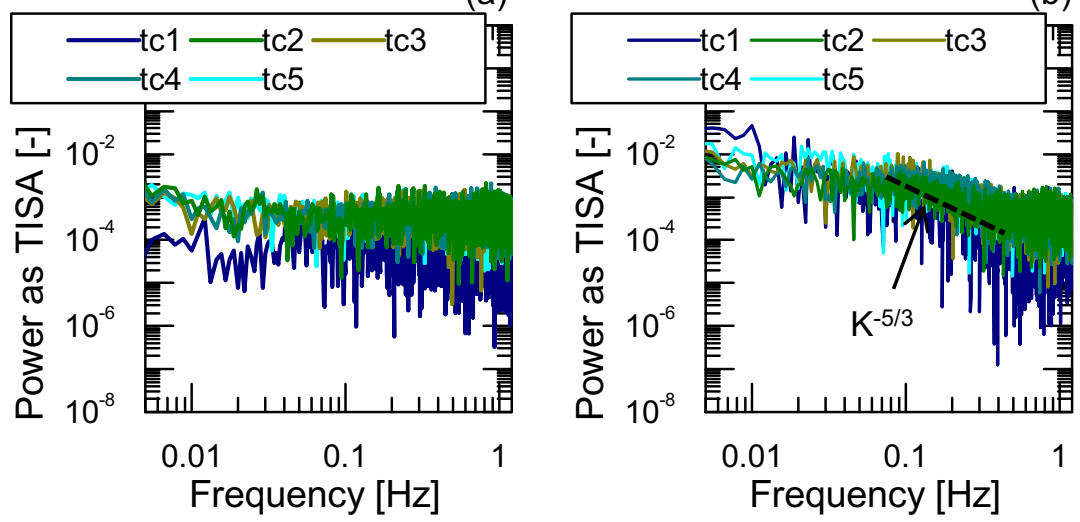

(c)
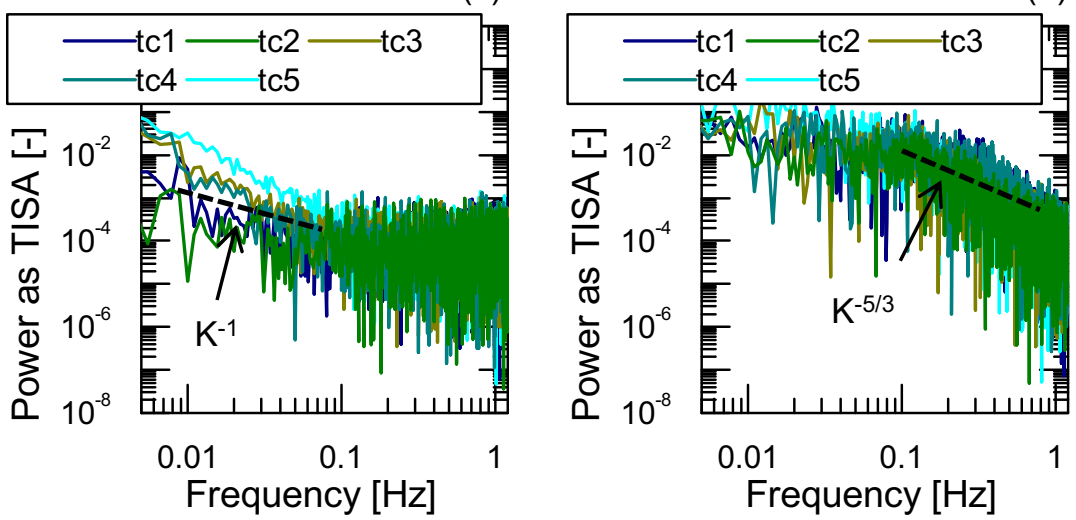

(e)

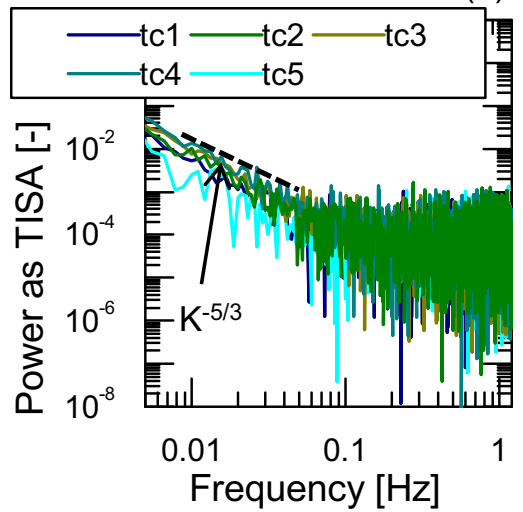

(b)

(d)

西 (f)

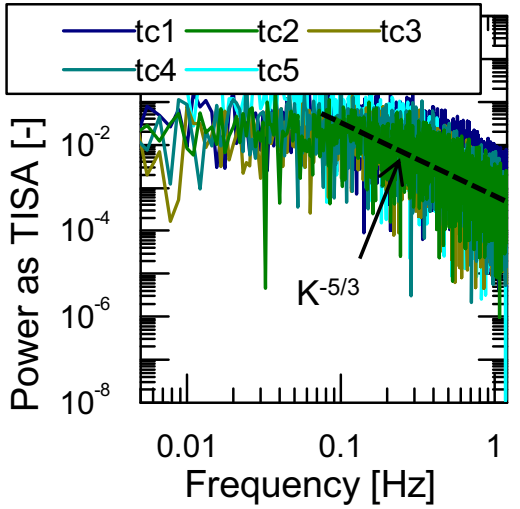

convective regime can be found for low frequencies. Applying magnetic induction to the system significantly changed the flow pattern. The spectral function became more inclined, suggesting that the flow field was destabilized. Partial matches to the inertial-convective regime were observed for all temperature differences.

In geometry with a high aspect ratio a flat power spectrum is characteristic only for the smallest temperature difference, in the case without the magnetic field applied. For temperature differences of 5 and $11{ }^{\circ} \mathrm{C}$ the spectrum of temperature variation in natural convection cases present slopes sharper than wave number to $-5 / 3$ exponent, indicating that the flow is in a transitional regime. After magnetic induction is applied, destabilization occurs and the power spectrum shows character similar to the inertial-convective regime. The conclusion for now is that a strong magnetic field breaks down irregular vortex structures in the fluid. Numerical simulations and visualization experiments must be performed to confirm this theory.

\section{Summary}

An experimental analysis of a magnetic field impact on a heat transfer and the behaviour of a fluid was conducted. Two 
Fig. 9 Power density as a function of a frequency in Enclosure no.2: (a) $b_{0 \max }=0 \mathrm{~T}$, $\Delta T=3{ }^{\circ} \mathrm{C}$, (b) $b_{0 \max }=10 \mathrm{~T}$, $\Delta T=3{ }^{\circ} \mathrm{C}$, (c) $b_{0 \max }=0 \mathrm{~T}$, $\Delta T=5^{\circ} \mathrm{C}$, (d) $b_{0 \max }=10 \mathrm{~T}$, $\Delta T=5{ }^{\circ} \mathrm{C}$, (e) $b_{0 \max }=0 \mathrm{~T}$, $\Delta T=11^{\circ} \mathrm{C}$, (f) $b_{0 \max }=10 \mathrm{~T}$, $\Delta T=11^{\circ} \mathrm{C}$ (a)
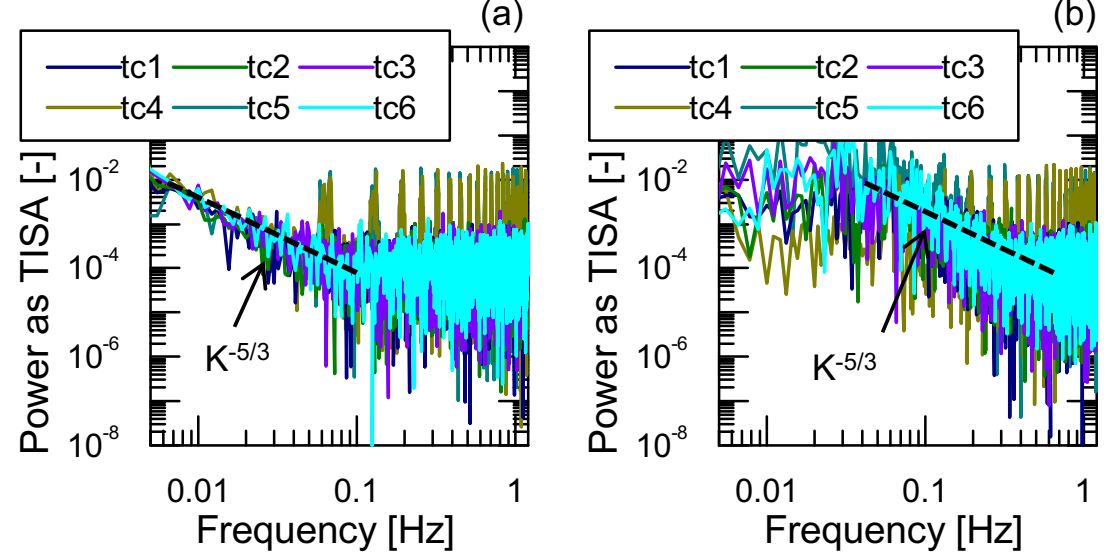

(c)

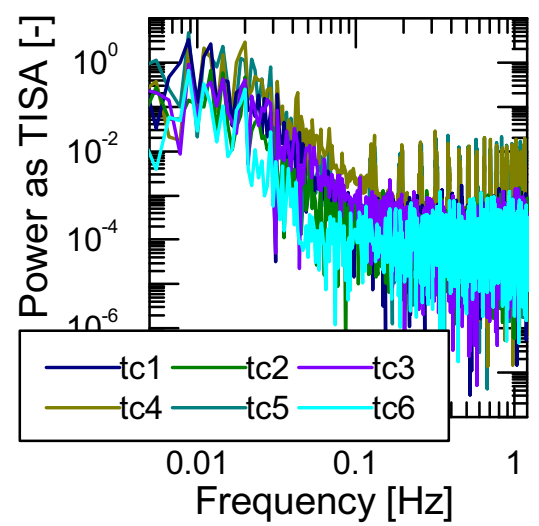

(d)

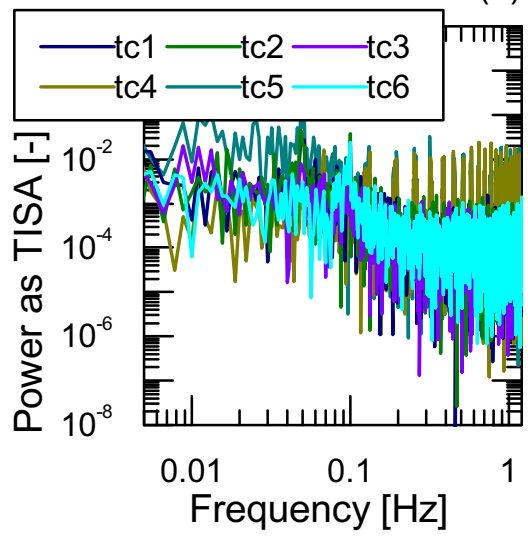

(e)

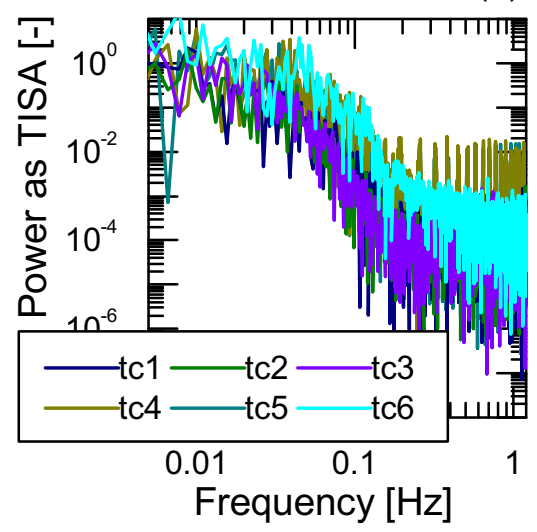

(f)

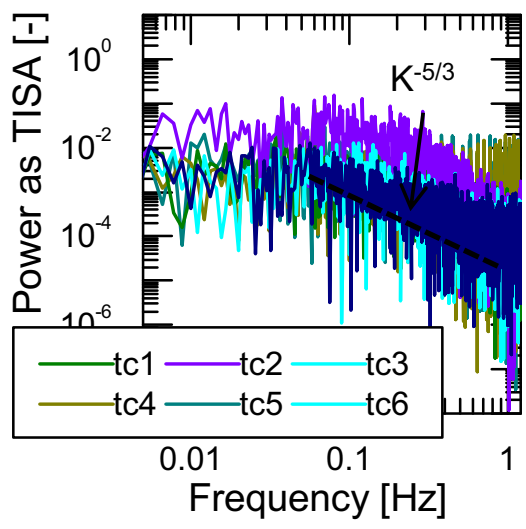

geometries of experimental enclosures were investigated: Enclosure no. 1 with an aspect ratio of 0.5 and Enclosure no.2 with a higher aspect ratio equal 2.0. Various magnetic field inductions were analysed and representative parts of the obtained results were shown in this paper.

The obtained results showed that the aspect ratio of the measurement vessel and the application of an external magnetic field to a magnetic fluid flow have an immense impact on heat transfer rate. While for Enclosure no. 1 the Nusselt number starts from 2.95 to 3.61, for Enclosure no. 2 heat transfer is almost at least four times greater for the natural convection cases. The performed analyses also demonstrated that magnetic field application to a magnetic fluid flow strongly enhances heat transfer. For every aspect ratio and all temperature differences, the magnetic induction increase from $0 \mathrm{~T}$ to $10 \mathrm{~T}$ caused an enhancement in heat transfer for at least $250 \%$. The performed spectral analysis allowed a conclusion that an external magnetic field applied to the system causes significant changes in the character of the flow. Introducing an additional new force - magnetic buoyancy one - to a convective motion causes intensification of fluid velocity. Large 
structures moving with low frequencies, under a strong magnetic field, transform to lower scales where energy dissipation occurs. Further studies, planned by the authors, will concentrate on numerical simulations for these cases and a thorough energy transport investigation.

Acknowledgments This work was supported by the National Science Centre (Project No. 12/07/B/ST8/03109).

Open Access This article is distributed under the terms of the Creative Commons Attribution 4.0 International License (http:// creativecommons.org/licenses/by/4.0/), which permits unrestricted use, distribution, and reproduction in any medium, provided you give appropriate credit to the original author(s) and the source, provide a link to the Creative Commons license, and indicate if changes were made.

\section{References}

1. Braithwaite D, Beaugnon E, Tournier R (1991) Magnetically controlled convection in a paramagnetic fluid. Nature 354:134-136

2. Tagawa T, Shigemitsu R, Ozoe H (2002) Magnetizing force modeled and numerically solved for natural convection of air in a cubic enclosure: effect of the direction of the magnetic field. Int $\mathrm{J}$ Heat Mass Transf 45:267-277

3. Bednarz T, Lei C, Patterson JC, Ozoe H (2009) Effects of a transverse, horizontal magnetic field on natural convection of a paramagnetic fluid in a cube. Int J Therm Sci 48:26-33

4. Bednarz T, Patterson JC, Lei C, Ozoe H (2009) Enhancing natural convection in a cube using a strong magnetic field - experimental heat transfer rate measurements and flow visualization. Int Commun. Heat Mass Transf 36:781-786

5. Bednarz T, Fornalik E, Tagawa T, Ozoe H (2006) Convection of paramagnetic fluid in a cube heated and cooled from side walls and placed below a superconducting magnet - comparison between experiment and numerical computations. J Therm Sci Eng Appl 14: $107-114$

6. Kenjereš S, Pyrda L, Wrobel W, Fornalik-Wajs E, Szmyd JS (2012) Oscillatory states in thermal convection of a paramagnetic fluid in a cubical enclosure subjected to a magnetic field gradient. Phys Rev E 85:1-8

7. Kenjereš S, Wrobel W, Pyrda L, Frnalik-Wajs E, Szmyd JS (2011) Transients and turbulence pockets in thermal convection of paramagnetic fluid subjected to strong magnetic field gradients. J Phys Conf Ser 318:072028

8. Pyrda L (2014) Application of fast Fourier transform in thermomagnetic convection analysis. J Phys Conf Ser 530:012060

9. Wrobel W, Szmyd JS (2010) International journal of heat and fluid flow experimental and numerical analysis of thermo-magnetic convection in a vertical annular enclosure. Int $\mathrm{J}$ Heat Fluid Flow 31: 1019-1031

10. Fornalik E, Filar P, Tagawa T, Ozoe H, Szmyd JS (2006) Effect of a magnetic field on the convection of paramagnetic fluid in unstable and stable thermosyphon-like configurations. Int J Heat Mass Transf 49:2642-2651

11. Postelnicu A (2004) Influence of a magnetic field on heat and mass transfer by natural convection from vertical surfaces in porous media considering Soret and Dufour effects. Int J Heat Mass Transf 47: $1467-1472$

12. Roszko A, Fornalik-Wajs E, Donizak J, Wajs J, Kraszewska A, Pleskacz L (2014) Magneto-thermal convection of low concentration nanofluids. MATEC Web Conf 18:03006

13. Azizian R, Doroodchi E, McKrell T, Buongiorno J, LW H, Moghtaderi B (2014) Effect of magnetic field on laminar convective heat transfer of magnetite nanofluids. Int J Heat Mass Transf 68:94-109

14. Ghasemi B, Aminossadati SM, Raisi A (2011) Magnetic field effect on natural convection in a nanofluid-filled square enclosure. Int $\mathrm{J}$ Therm Sci 50:1748-1756

15. Turan O, Poole RJ, Chakraborty N (2012) Influences of boundary conditions on laminar natural convection in rectangular enclosures with differentially heated side walls. Int J Heat Fluid Flow 33:131146

16. Bai B, Yabe A, Qi J, Wakayama NI (1999) Quantitative Analysis of Air Convection Caused by Magnetic-Fluid Coupling. AIAA Journal 37 (12):1538-1543. https://doi.org/10.2514/2.652

17. Pyrda L (2013) An analysis of magnetic field influence on transient regime between laminar and turbulent convection. Dissertation, AGH University of Science and Technology

18. Ozoe H, Churchill SW (1973) Hydrodynamic stability and natural convection in Newtonian and non-Newtonian fluids heated from below. AIChe Symp Ser, Heat Transfer 69(131):126-133

19. Elsner JW (1989) Turbulencja przepływów (Turbulence of Flows). PWN, Warszawa

20. Kraszewska A, Pyrda L, Donizak J (2016) Experimental analysis of enclosure aspect ratio influence on thermo-magnetic convection hest transfer. J Phys Conf Ser 745:032153 